\title{
Demographic and Sexual Behavior Characteristics of Men Who Have Sex with Men (MSM) Registered in a Targeted Intervention (TI) Program in India
}

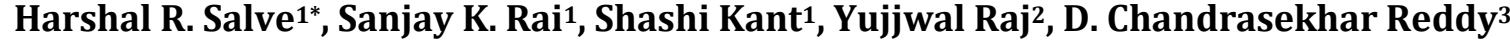 \\ ${ }^{1}$ Centre for Community Medicine, All India Institute of Medical Sciences, New Delhi, India \\ ${ }^{2}$ Ex-NPO National AIDS Control Organiation, Government of India, New Delhi, India \\ ${ }^{3}$ Ex-Professor IMS BHU and Ex-NPO WHO Country Office, New Delhi, India \\ Email: ${ }^{*}$ harshalsalve@ymail.com
}

Received 20 August 2015; accepted 22 September 2015; published 25 September 2015

Copyright @ 2015 by authors and Scientific Research Publishing Inc.

This work is licensed under the Creative Commons Attribution International License (CC BY). http://creativecommons.org/licenses/by/4.0/

c) (i) Open Access

\section{Abstract}

Background: Men who have sex with men (MSM) contribute substantially to HIV prevalence in India. The targeted intervention (TI) program is the most important link between MSM and the public health system. Hence, we studied the demographic and sexual behavior characteristics of MSM registered in TI program in India. Methods: We used information maintained at TI sites under the program catering exclusively to MSM in India. Demographic characteristics and sexual behavior of MSM over the past two decades were also studied. Risk behaviors included type of partners, alcohol use, sexual acts per week, years of sex work and age at initiation of sex work. Bivariate analysis was carried out to understand the demographic determinants of sexual behavior. Results: In total, data of 6037 MSMs from 14 TI sites were analyzed. Of these $4655(73.8 \%)$ were young adults ( $<35$ years) and $2565(40.8 \%)$ had completed their matriculation. More than half $(55.4 \%)$ were married. Double-decker was identified as the most common sub-typology among MSM. Average age of initiation of sex was 23.0 years and average number of sexual acts per week was 6.8 (95\% CI: 6.8 - 7.0). Irregular partners and alcohol use were observed in $30.5 \%$ and $52.8 \%$ of MSM respectively. Cohort analysis revealed a statistically significant declining trend in average age of initiation of sex over the past two decades. The sexual behavior of MSM varied significantly by employment status, education, marital status, state of residence, alcohol use and type of sex partner. Conclusion: MSMs registered with the TI program in India were mostly young, educated, and employed. Many MSM also had a history of heterosexual relationships, and thus had the potential of transmitting HIV infection to the otherwise low risk general population. This analysis supports the use of TI program data for understanding the demographic and sexual behavior characteristics of "Corresponding author. 
hard to reach and stigmatized population in society.

Keywords

Men Who Have Sex with Men, Demographic Profile, Sexual Behavior, India

\section{Introduction}

Globally, India ranked third in the number of HIV infected people in the year 2010 [1]. Though the HIV epidemic in India has shown a declining trend over the last decade, higher prevalence rates were observed in specific population sub-groups [2]. In India, the HIV epidemic is driven by unprotected sexual intercourse and intravenous drug use [2], which contributed to higher HIV prevalence in these population sub-groups in India [2]. Hence, these population sub-groups were labeled as high-risk groups (HRG). These HRG include female sex workers (FSWs), men who have sex with men (MSM), male-to-female transgender (TG/Hijra) and injecting drug users (IDUs) [2]. In 2010 the highest HIV prevalence was reported among Transgenders (TGs) (8.82\%) followed by IDUs (7.14\%) and MSM (4.43\%) [3].

National AIDS Control Organization (NACO) has implemented targeted intervention (TI) programs for HRGs in India [4]. Civil society, non-government organizations (NGOs) and State AIDS Control Societies were stakeholders in the program. Under the TI program, MSMs were of four types namely Kothi (primarily receptive), Panthi (primarily insertive), double-decker (DD) (engaged in both roles), and Hijra. Hijras are a distinct socio-religious and cultural group, a "third gender" (apart from male and female). This population usually dresses in feminine attire (cross-dress) and is organized under seven main gharanas (clans). For the purpose of TIs, Hijras are covered under the term "transgender" (TGs) [4].

Moreover, prevalence of sexually transmitted infections was also high among MSMs and TGs [5] [6]. The problem was further complicated by social stigma and discrimination associated with MSM in India [7]. This contributed to inadequate access to preventive services and poor service utilization by MSM, which made them more vulnerable to HIV [6] [8]. Due to social pressure, most MSM in India were forced to engage in heterosexual relationships with their spouse [6]. Therefore, MSM served as a source of HIV infection for the general population [9].

Chow EP et al. reported that lack exposure to HIV related preventive and promotive services responsible for higher unprotected sexual activity among MSM [10]. Globally, studies also reported that social support and health education has positive impact on quality of life of MSM [11] [12]. Interventions such as care, support and treatment to prevent the spread of HIV among HRGs were being implemented through the TI program in India [4]. Though the TI program reached only $71 \%$ of the estimated MSM population, it remained their only source of contact with the government health system [1]. The TI program has collected information on the demographic characteristics and high-risk behavior of the MSM population. Studies reported that demographic characteristics of MSM are the important determinants of risk behavior globally [13] [14]. Hence, we analyzed this demographic and behavior characteristics profile of MSM registered under TI program, in order to suggest measures to strengthen interventions under this program.

\section{Methods}

\subsection{Study Setting}

The study was carried out under the ambit of National AIDS Control Organization (NACO's) TI program in India. We analyzed individual level information from the master register (Form E) maintained at TI sites.

\subsection{Study Population}

MSMs registered under the TI program were included in the study.

\subsection{Sampling Strategy}

We categorized the states in India as per geographical representation (North, South, East, West) and HIV preva- 
lence amongst MSM (in 2012) (>10\%, 5\% - 10\%, 1\% - 4.9\% and <1\%) [1]. Out of 29 states, 16 states were selected for obtaining a list of TIs catering exclusively to MSM. TIs sites that were operational since 2007 and were able to provide data for the identified study period (January 2013-December 2013) were included in the analysis. A schematic representation of sampling method is presented in Figure 1.

\subsection{Data Extraction}

Data from the master register (Form E) maintained at TI sites was provided by NACO. The master register at TI sites was maintained by the outreach workers (ORWs) and updated annually [4]. In the register, each MSM was identified with a unique number. Individual level information on age, typology, occupation, education, marital status sexual acts per week, partner type (regular/irregular), years of sex work, and alcohol use were extracted from Form E. Duplication in TI data was eliminated by using the unique ID given to each MSM at the TI site.

\subsection{Data Analysis}

Cohort analysis was carried out to understand the trend in MSMs' demographic characteristics and high-risk behavior over two decades (1993-2013). Five-year cohorts were made by calculating the year of initiation of sex work, using information on current age and years of sex work, and taking 2013 as the base year. For example, if age of the MSM was 45 years, and engagement in sex work was 10 years, then the year of initiation of sex work would be 35 years, which would be considered to be 2003; hence this particular MSM would be categorized into cohort II (1998-2003). In this way, four cohorts were created representing the year of initiation of sex work by MSM: Cohort I (1993-1997), Cohort II (1998-2003), Cohort III (2004-2008) and Cohort IV (2009-2013). Variations of demographic and sexual behavior characteristics across the cohorts were assessed using chi-square for trend.

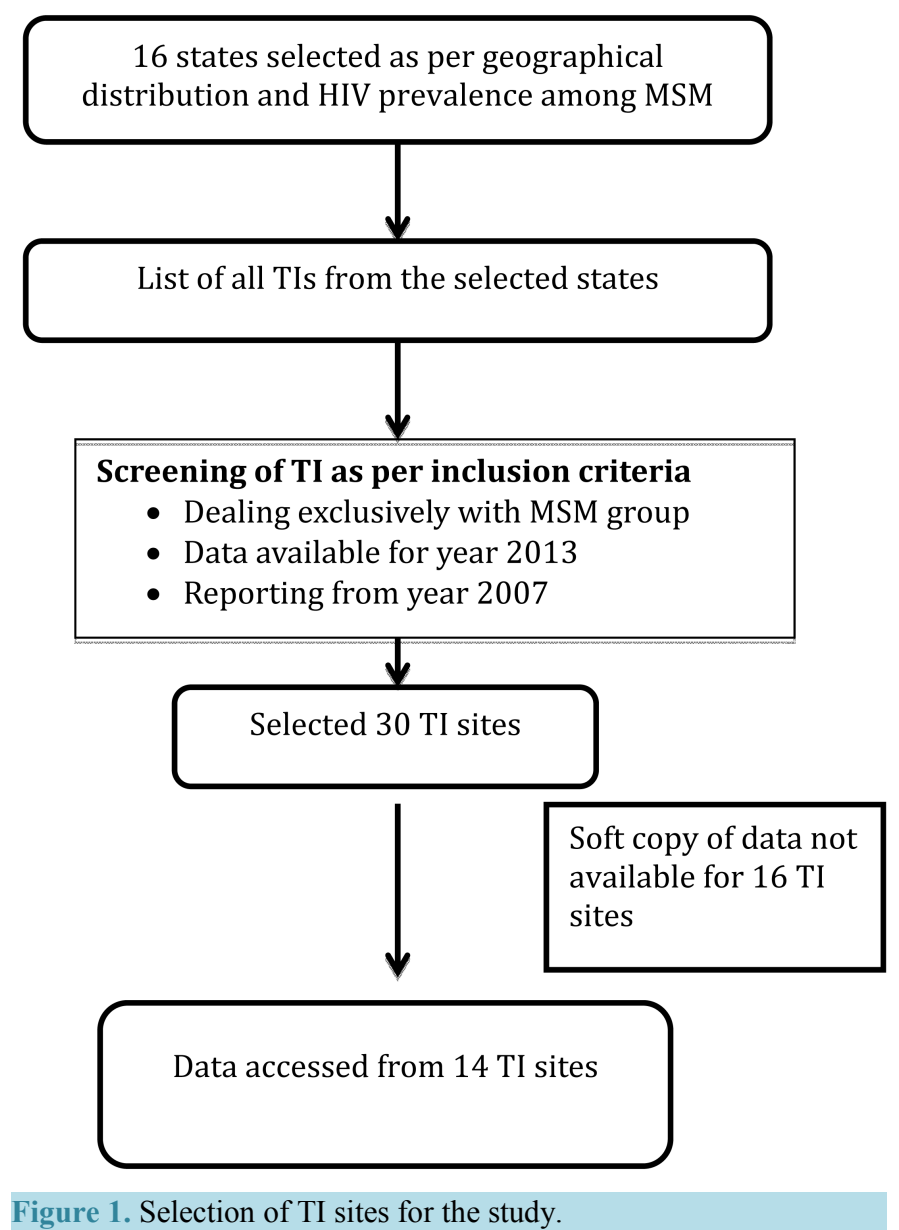


Data from 14 MSM TIs sites were included in the analysis. These TI sites were spread across five states namely, Andhra Pradesh, Assam, Karnataka, Maharashtra, and Manipur, of which Maharashtra and Manipur are categorized as high HIV prevalence states. All other states are classified as low HIV prevalence states as per HIV prevalence among MSM. In total, information from 6161 MSMs was extracted from "Form E" from selected TI sites. Out of this, data of $102(1.7 \%)$ MSMs were removed due to data errors. The data errors included, missing information, and erroneous entries. A total of $22(0.4 \%)$ MSMs in which death was reported were excluded from the analysis. Finally 6037 individual MSM records were analyzed.

Data were extracted into Microsoft Excel for Windows format. Univariate analysis was done and the results expressed as numbers and proportions. Bivariate analysis was done to study the association between demographic characteristics (age, education, occupation, typology, and residence) and high-risk behavior (type of partner, sexual acts per week, age of initiation of sex work, and alcohol use). Chi square test was applied to assess statistical significance. Results were reported along with $95 \%$ confidence intervals (CIs). P value $<0.05$ was considered as statistically significant. Chi-square tests were used for cohort analysis. Data analysis was done using STATA version 9.0.

\subsection{Ethical Considerations}

The Institutional Review Board of NACO approved the study. Personal identifiers were removed from the analysis to maintain the confidentiality.

\section{Results}

\subsection{Demographic Profile}

Of a total of 6037 MSM, 4521 (71.7\%) belonged to the age group 20 - 35 years, with a mean age of 31.5 years (SD: 7.6) (Table 1). Illiteracy was reported in 1506 MSM (23.9\%). Matriculation and above education was completed by 2565 MSM (40.8\%). Of the total, 3524 MSMs (55.9\%) were married, and 1142 (18.3\%) were never employed in their lifetime. Double-decker $(3233,51.4 \%)$ was the commonest sub-typology of MSM, followed by Kothis, TGs and Panthis (2419 [38.4\%]; 417 [7.8\%] and 79 [1.4\%] respectively). Lifetime use of alcohol was reported by 3030 MSMs (52.8\%) (Table 1).

\subsection{Sexual Behavior}

The mean number of years of sex work reported by MSM was 9.0 years (95\% CI: $8.9-9.2)$, and average number of sexual act per week 6.8 (95\% CI: 6.7 - 7.0). Average age at initiation of sex was 23.0 years (95\% CI: 22.8 23.1). Information about type of partners (irregular/regular) was available only for 4100 MSMs $(67.9 \%)$. Out of these, 1251 (30.5\%) reported having had sex with irregular partners (Table 1). Of the total MSM, $1829(29.0 \%)$ dropped out of the TI program during the study period.

Over the last two decades, the average age at initiation of sex work among MSM showed a significant increase from 20.9 years $(1993)$ to 24.5 years $(2013)(\mathrm{p}<0.001)$. The average number of sex acts per week and alcohol use revealed a statistically significant declining trend over the past two decades in cohort analysis (Table 2). The proportion of MSM who reported irregular partners increased over the past two decades from $6.9 \%$ (1993) to $26.9 \%$ (2013). No other clear pattern emerged in the cohort analysis (Table 2).

\subsection{Association between Selected Socio-Demographic Factors and Risk Behavior}

MSM registered in the TI program in the high prevalence states (HIV prevalence in MSM $\geq 10 \%$ ) reported more high-risk behavior such as early age at initiation of sex (22.6 vs. $23.9, \mathrm{p}<0.001)$, alcohol use $(56.7 \%$ vs. $23.9 \%$, $\mathrm{p}<0.001)$ and higher average number of sexual act per week $(8.1$ vs. $4.2, \mathrm{p}<0.001)$ as compared to those in low prevalence states. These associations were statistically significant. There was no statistically significant difference in illiteracy status $(\mathrm{p}=2.7)$ and employment status $(\mathrm{p}=0.5)$ between high and low HIV prevalence states (Table 3 ).

There was no statistically significant difference in high-risk behavior by typology, except for alcohol use ( $\mathrm{p}<$ $0.001)$ and type of partner $(p=0.005)$. Marital status $(p<0.001)$ and employment status $(p<0.001)$ varied significantly by MSM typology (Table 4). The average number of sexual acts per week was significantly higher in 
Table 1. Demographic and risk behavior profile of MSM registered in TI Program (N: 6037).

\begin{tabular}{|c|c|c|c|}
\hline Demographic characteristics & Categories & Frequency $(\mathrm{N})$ & Percentage \\
\hline \multirow{4}{*}{ Age (years) } & $<20$ & 134 & 2.1 \\
\hline & $20-35$ & 4521 & 71.7 \\
\hline & $36-49$ & 1487 & 23.6 \\
\hline & $\geq 50$ years & 165 & 2.6 \\
\hline \multirow{2}{*}{ Marital status } & Never married & 2783 & 44.1 \\
\hline & Ever married & 3524 & 55.9 \\
\hline \multirow{7}{*}{ Education status } & Illiterate & 1506 & 23.9 \\
\hline & Literate & 454 & 7.2 \\
\hline & Primary education & 917 & 14.6 \\
\hline & Middle school education & 853 & 13.6 \\
\hline & Matriculation/higher Secondary education & 2096 & 33.3 \\
\hline & Graduate and above & 469 & 7.5 \\
\hline & Information not available & 12 & 0.1 \\
\hline \multirow{7}{*}{ Occupation } & Never employed & 1142 & 18.3 \\
\hline & Currently unemployed & 436 & 7.0 \\
\hline & Full time employed & 1036 & 16.5 \\
\hline & Part time employed & 1395 & 23.5 \\
\hline & Student & 255 & 4.1 \\
\hline & Others & 146 & 2.3 \\
\hline & Information not available & 62 & 0.9 \\
\hline \multirow{5}{*}{ State of Residence } & Andhra Pradesh & 3852 & 61.1 \\
\hline & Assam & 339 & 5.9 \\
\hline & Karnataka & 1132 & 18.0 \\
\hline & Maharashtra & 516 & 8.2 \\
\hline & Manipur & 466 & 7.4 \\
\hline \multirow{4}{*}{ Typology of MSM } & Double-decker & 3233 & 51.4 \\
\hline & Kothi & 2419 & 38.4 \\
\hline & Hijra/TG & 417 & 7.8 \\
\hline & Panthi & 79 & 1.4 \\
\hline \multirow{3}{*}{ Alcohol use ever } & Yes & 3030 & 48.0 \\
\hline & No & 2700 & 42.8 \\
\hline & Information not available & 577 & 9.2 \\
\hline \multirow{3}{*}{ Partner type } & Regular & 2849 & 45.2 \\
\hline & Irregular & 1251 & 19.8 \\
\hline & Information not available & 2207 & 34.0 \\
\hline Sexual acts per week & (Mean, $95 \% \mathrm{CI}$ ) & $6.8(6.7-7.0)$ & - \\
\hline Years in sex work & (Mean, 95\% CI) & $9.0(8.9-9.2)$ & - \\
\hline Age at initiation of sex work & (Mean, $95 \% \mathrm{CI}$ ) & $23.0(22.9-23.1)$ & - \\
\hline
\end{tabular}


Table 2. Distribution of demographic and risk behavior characteristics by cohort.

\begin{tabular}{|c|c|c|c|c|c|}
\hline Variable & $\begin{array}{l}\text { Cohort I } \\
(1993-1997)\end{array}$ & $\begin{array}{l}\text { Cohort II } \\
(1998-2003)\end{array}$ & $\begin{array}{l}\text { Cohort III } \\
(2004-2008)\end{array}$ & $\begin{array}{l}\text { Cohort IV } \\
(2009-2013)\end{array}$ & $\mathrm{p}$ value \\
\hline No. $(\%)$ & $515(9.3)$ & $822(14.8)$ & $2170(39.0)$ & $2054(36.9)$ & - \\
\hline $\begin{array}{l}\text { Number of sexual acts per } \\
\text { week (Mean, SD) }\end{array}$ & $7.7(5.0)$ & $7.5(5.2)$ & $7.5(5.2)$ & $6.1(4.9)$ & $<0.001$ \\
\hline $\begin{array}{l}\text { Age at initiation of sex work } \\
\text { (years) (Mean, SD) }\end{array}$ & $20.9(5.2)$ & $20.8(5.4)$ & $22.8(5.6)$ & $24.5(5.2)$ & $<0.001$ \\
\hline Irregular partners $(\%)^{*}$ & $36(6.9)$ & $52(6.3)$ & $283(13.0)$ & $615(29.9)$ & $<0.001$ \\
\hline Alcohol use (\%) & $229(44.4)$ & $427(51.9)$ & $1129(52.0)$ & 749 (36.4) & $<0.001$ \\
\hline Illiteracy (\%) & $120(23.3)$ & $167(20.3)$ & $486(22.4)$ & $505(24.6)$ & 0.08 \\
\hline Higher education (\%) & $225(43.7)$ & $374(45.5)$ & $933(43.0)$ & $765(37.2)$ & $<0.001$ \\
\hline Never employed (\%) & $84(16.3)$ & $188(22.8)$ & $494(22.8)$ & 404 (19.7) & 0.002 \\
\hline
\end{tabular}

*Only 5561 MSM included. Bold: Statistically significant at 5\%.

Table 3. Distribution of demographic characteristics and high-risk behavior characteristics by HIV prevalence in states.

\begin{tabular}{|c|c|c|c|c|}
\hline Risk behavior & High prevalence states & Low prevalence states & Total & $\mathrm{p}$ value \\
\hline No. of MSM (\%) & $4320(68.5)$ & $1987(31.5)$ & 6307 & - \\
\hline $\begin{array}{l}\text { Sexual acts per week } \\
\quad(\text { Mean, } 95 \% \mathrm{CI})\end{array}$ & $8.1(8.3-8.6)$ & $4.2(4.1-4.4)$ & $6.8(6.8-7.0)$ & $<0.001$ \\
\hline $\begin{array}{l}\text { Years of sex work } \\
\text { (Mean, } 95 \% \mathrm{CI} \text { ) }\end{array}$ & $10.2(9.9-10.4)$ & $6.7(6.5-7.0)$ & $9.0(8.9-9.2)$ & $<0.001$ \\
\hline $\begin{array}{l}\text { Age at initiation of sex work (Mean, } \\
95 \% \mathrm{CI})\end{array}$ & $22.6(22.5-22.8)$ & $23.9(23.6-24.1)$ & $23.0(22.9-23.1)$ & $<0.001$ \\
\hline Irregular partners (\%) & $524(12.1)$ & $707(36.6)$ & $1251(19.8)$ & $<0.001$ \\
\hline Alcohol use (\%) & $2080(56.7)$ & $454(23.9)$ & $2534(45.6)$ & $<0.001$ \\
\hline Illiteracy (\%) & $1057(22.9)$ & 449 (22.9) & $1506(23.9)$ & 2.7 \\
\hline Never employed (\%) & $773(18.0)$ & $369(18.7)$ & $1142(18.3)$ & 0.5 \\
\hline
\end{tabular}

*Only 5561 MSM included. Bold: Statistically significant at 5\%.

Table 4. Relationship between selected variables and typology of MSM.

\begin{tabular}{cccccc}
\hline Risk behavior & Kothi & Double-decker & Panthi & Hijra/TG & p value \\
\hline Sexual acts per week (Mean, SD) & $6.7(5.1)$ & $7.0(5.0)$ & $7.3(4.5)$ & $6.7(4.5)$ & 0.7 \\
Years of sex work (Mean, SD) & $8.8(6.6)$ & $9.2(6.9)$ & $9.3(6.4)$ & $9.2(6.7)$ & 0.1 \\
Age at initiation of sex work (years) & $23.0(5.7)$ & $23.0(5.7)$ & $22.8(5.5)$ & $23.0(5.8)$ & 0.9 \\
(Mean, SD) & $1125(39.5)$ & $1458(51.2)$ & $62(2.2)$ & $204(7.2)$ & $\mathbf{0 . 0 0 5}$ \\
Irregular partners (\%) & $1211(50.6)$ & $1510(46.7)$ & $88(52.9)$ & $221(4543)$ & $<\mathbf{0 . 0 0 1}$ \\
Alcohol use (\%) & $641(26.6)$ & $686(21.2)$ & $29(17.3)$ & $153(31.6)$. & $<\mathbf{0 . 0 0 1}$ \\
Illiteracy (\%) & $724(39.6)$ & $305(9.5)$ & $8(4.7)$ & $105(21.6)$ & $<\mathbf{0 . 0 0 1}$ \\
Never employed (\%) & $1300(53.4)$ & $1861(57.6)$ & $70(41.7)$ & $293(60.2)$ & $<\mathbf{0 . 0 0 1}$ \\
Married (\%) & & & &
\end{tabular}

Bold: Statistically significant at 5\%.

illiterate MSM as compared to literate MSM (7.1 vs. 6.8; $\mathrm{p}=0.01$ ), whereas MSM who were never employed had more irregular partners as compared employed MSM (21.6\% vs. $19.6 \% ; \mathrm{p}=0.04)$.

The proportion of MSM who dropped out of the TI program was higher among those with a history of use of 
alcohol $(36.6 \%$ vs. $26.6 \%$; $<<0.001)$ and those residing in high HIV prevalence states $(41.7 \%$ vs. $1.4 \%$; $<<$ $0.001)$. Higher dropout rate was observed among MSM with a higher average number of sexual acts per week ( $\mathrm{p}<$ $0.001)$, and those who were unemployed $(\mathrm{p}=0.03)$.

\section{Discussion}

The demographic characteristics of MSM observed in this study are similar to previous studies based on HIV Sentinel Surveillance (HSS) data in India [6] [15]. Almost-two thirds of MSM belonged to the younger age group ( $<35$ years). Jha et al. have reported similar findings [16]. More than one-third of all MSMs had completed matriculation or higher education. The predominance of higher education status in MSM in this study might be due to higher awareness and accessibility of TI services among educated MSMs [17] [18]. One-fourth of MSM were part-time employees, and one-fifth were never employed. Thus a significant proportion of MSM might have depended, at least partially, on sex work as a source of income. More than half of MSM were ever married. This provided a route for heterosexual transmission of HIV infection from high-risk MSM to the general population [9].

Double-decker was the predominant sub-typology identified in the TI program. This finding is contrary to the results of various studies, which indicate that Kothis are the dominant sub-typology in India attributed to their self-identifiable nature as compared to other sub-typologies [6] [15]. Corroborating with other studies, the proportion of Panthis in our study was also low. This could be due to the hidden nature of this sub-typology. Also, Panthis, being the insertive partner, mostly identify themselves as heterosexual [6]. Alcohol use was reported by almost half the MSM and it was higher in the Panthi sub-typology as compared to others. Alcohol use has been identified as an important determinant of HIV-related risk behaviors in MSM both nationally [19] and internationally [20] [21].

MSM in high prevalence states reported a higher number of sexual acts per week. Though this association was statistically significant, because of the minimal difference in numbers (7.1 vs. 6.8), its programmatic implications are doubtful. Other things being equal, the higher number of sexual acts makes these MSM more vulnerable to acquisition of HIV infection than others [6]. Illiterate MSM had reported higher sexual activity, unlike other studies in India [6] [15]. The reason(s) for the difference is not clear.

Cohort analysis revealed a statistically significant increase in the age at initiation of sex work over the past two decades. This could be attributed to empowerment of MSM over the years. However, this needs to be further explored. A statistically significant difference in sexual behavior across high and low HIV prevalence states was identified in our study. This could be due to ascertainment bias; information may have been more rigorously sought in high prevalence states. Alternatively, it may be a reflection of the actual status. We found that unemployed MSM having more sexual activity had a higher tendency to drop-out of the TI program. This would result in MSM at high risk of HIV infection moving out of the ambit of care, support and treatment services of the TI program.

This study has a few limitations too. First, out of 30 -selected TI sites in this study, data from only 14 TI sites from five states were available for the analysis. Therefore, the findings of this study cannot be generalized to MSMs registered in other TI sites. The available information pertains to MSM registered with the TI sites. MSMs not registered with TI sites may or may not be similar to those who were registered. Therefore, the program data may not be representative of the entire MSM population in India [6]. We therefore suggest that the findings of this study may be interpreted cautiously. Second, data on risk behavior collected at the TI sites were for programmatic purposes and not for the research. Hence, the robustness of the data may be questioned. Third, TI program data did not have information on the number of partners, unprotected sex and condom use among MSM. This would have been vital to gain more insight into their high-risk behavior.

In this study, we have described the demographic and risk behavior characteristics of MSM enrolled in the TI program in India. The number of MSM included in our study is large. The large sample size allowed us to identify statistical significance even where the differences were small. In addition we have larger geographical representation as compared to previous studies in India [6] [9] [15] [22].

\section{Conclusions}

Our analysis of TI program data provided vital demographic and risk-behavior related information on MSM, one of the most highly stigmatized and marginalized population groups in society. Risk behaviors of MSM regis- 
tered in the TI program were associated with educational status, occupation status and HIV prevalence in state of residence. Over the past two decades, the age of initiation of sex among MSMs had increased. There is need for further research to gain more insight into its determinants and implications. Drop-out from the program was observed more in MSM using alcohol. Also, a higher frequency of drop-out from the program was observed among those unemployed, and those reporting higher sexual acts per week. Hence, MSM with these characteristics need more counseling to retain them in the TI program.

MSM engaging in heterosexual behavior pose a risk of HIV transmission to the general population. The TI program is the only link between this highly vulnerable and marginalized population and the health system. Hence, strengthening of the TI program in terms of scaling up the program, regular monitoring of program data and operational research are necessary for further effectiveness of prevention and control of HIV in this HRG.

\section{Acknowledgements}

This paper (NACO/SIMU/NDAP/2015/09) was written as part of the National Data Analysis Plan (NDAP), an initiative of the Strategic Information Management Unit of National AIDS Control Organization (NACO), Ministry of Health and Family Welfare, Government of India. We would like to thank the various divisions of NACO and State AIDS Control Organization (SACS) that have collected and maintained the program data. This paper was conceptualized, developed and finalized by the author, under the guidance of mentors (senior public health experts) and the NDAP Unit, NACO. The Knowledge Network project of the Population Council, which is a grantee of the Bill \& Melinda Gates Foundation though Avahan, the India AIDS Initiative, has supported the scientific writing, reviewing, editing and finalization of this paper. This project was also supported by NACO's other development partners, which include Center for Diseases Control (CDC), World Health Organization-India, FHI-360, and John Snow India. The views expressed in this paper are those of the authors, and do not necessarily reflect the views of NACO.

\section{Conflict of Interest}

None declared.

\section{References}

[1] Annual Report 2012-2013 (2013) National AIDS Control Organization; Ministry of Health \& Family Welfare, Government of India. http://www.naco.gov.in/upload/Publication/Annual\%20Report/Annual\%20report\%202012-13 English.pdf

[2] Annual Report 2011-2012 (2012) National AIDS Control Organization; Ministry of Health \& Family Welfare, Government of India. http://nacoonline.org/NACO/Quick_Links/Publication/Annual_Report/NACO Annual_Report/NACO Annual_Report 2011-12 English/

[3] HIV Sentinel Surveillance 2010-2011 (2012) A Technical Brief National AIDS Control Organization; Ministry of Health \& Family Welfare, Government of India. http://www.nacoonline.org/NACO

[4] Targeted Interventions under NACP III National AIDS Control Organization (2013) Ministry of Health \& Family Welfare, Government of India. http://www.nacoonline.org/NACO

[5] Chakrapani, V., Newman, P.A. and Shunmugam, M. (2008) Secondary HIV Prevention among Kothi Identified MSM in Chennai, India. Cult Health Sex, 10, 313-327. http://dx.doi.org/10.1080/13691050701816714

[6] Saha, M.K., Mahapatra, T., Biswas, S., Ghosh, P. and Kire, M. (2015) Burden and Correlates of HIV Risk among Men Who Have Sex with Men in Nagaland, India: Analysis of Sentinel Surveillance Data. PLoS ONE, 10, e 0117385.

[7] Brahmam, G.N., Kodavalla, V., Rajkumar, H., Rachakulla, H.K., Kallam, S., et al. (2008) Sexual Practices, HIV and Sexually Transmitted Infections among Self-Identified Men Who Have Sex with Men in Four High HIV Prevalence States of India. AIDS, 22, S45-S57. http://dx.doi.org/10.1097/01.aids.0000343763.54831.15

[8] Kumar, B. and Ross, M. (1991) Sexual Behavior and HIV Infection Risks in Indian Homosexual Men: A Cross-Cultural Comparison. International Journal of STD \& AIDS, 2, 442-444.

[9] Thomas, B., Mimiaga, M.J., Menon, S., Chandrasekaran, V., Murugesan, P., Swaminathan, S., et al. (2009) Unseen and Unheard: Predictors of Sexual Risk Behavior and HIV Infection among Men Who Have Sex with Men in Chennai, India. Aids Education and Prevention, 21, 372-383. http://dx.doi.org/10.1521/aeap.2009.21.4.372

[10] Chow, E.P., Chen, X., Zhao, J., Zhuang, X., Jing, J. and Zhang, L. (2015) Factors Associated with Self-Reported Un- 
protected Anal Intercourse among Men Who Have Sex with Men in Changsha City of Hunan Province, China. AIDS Care, 14, 1-11. [Epub ahead of print]. http://dx.doi.org/10.1080/09540121.2015.1058892

[11] Liu, J., Qu, B., Zhu, Y.X. and Hu, B.X. (2015) The Influence of Social Support on Quality of Life of Men Who Have Sex with Men in China: A Preliminary Study. PLoS ONE, 10, e 0127644. http://dx.doi.org/10.1371/journal.pone.0127644

[12] Chen, J.P., Han, M.M., Liao, Z.J., Dai, Z.Z., Liu, L., Chen, H., et al. (2015) HIV-Related Behaviors, Social Support and Health-Related Quality of Life among Men Who Have Sex with Men and Women (MSMW): A Cross-Sectional Study in Chongqing, China. PLoS ONE, 10, e0118651. http://dx.doi.org/10.1371/journal.pone.0118651

[13] Baral, S.D., Friedman, M.R., Geibel, S., Rebe, K., Bozhinov, B., Diouf, D., et al. (2015) Male Sex Workers: Practices, Contexts, and Vulnerabilities for HIV Acquisition and Transmission. The Lancet, 385, 260-273. http://dx.doi.org/10.1016/s0140-6736(14)60801-1

[14] Wagner, G.J., Tohme, J., Hoover, M., Frost, S., Ober, A., Khouri, D., et al. (2014) HIV Prevalence and Demographic Determinants of Unprotected anal Sex and HIV Testing among Men Who Have Sex with Men in Beirut, Lebanon. Archives of Sexual Behavior, 43, 779-788. http://dx.doi.org/10.1007/s10508-014-0303-5

[15] Mahapatra, T., Biswas, S., Nandi, S., Ghosh, P., Ghosh, M., Mondal, S., et al. (2015) Burden and Correlates of HIV among Men Who Have Sex with Men in West Bengal, India: Analysis of Sentinel Surveillance Data. PLoS ONE, 10, e0127232. http://dx.doi.org/10.1371/journal.pone.0127232

[16] Jha, U.M., Raj, Y., Venkatesh, S., Dhingra, N., Paranjpe, R.S. and Saggurti, N. (2014) HIV Epidemic among Men Who Have Sex with Men in India: National Scenario of an Unfinished Agenda. HIV AIDS, 6, 159-170.

[17] Setia, M.S., Lindan, C., Jerajani, H., Kumta, S., Ekstrand, M., Mathur, M., et al. (2006) Men Who Have Sex with Men and Transgenders in Mumbai, India: An Emerging Risk Group for STIs and HIV. Indian Journal of Dermatology, Venereology and Leprology, 72, 425-431. http://dx.doi.org/10.4103/0378-6323.29338

[18] Khan, S. (2001) Culture, Sexualities, and Identities: Men Who Have Sex with Men in India. Journal of Homosexuality, 40, 99-115. http://dx.doi.org/10.1300/J082v40n03 06

[19] Yadav, D., Chakrapani, V., Goswami, P., Ramanathan, S., Ramakrishnan, L., George, B., et al. (2014) Association between Alcohol Use and HIV-Related Sexual Risk Behaviors among Men Who Have Sex with Men (MSM): Findings from a Multi-Site Bio-Behavioral Survey in India. AIDS and Behavior, 18, 1330-1338.

[20] Reisner, S.L., Mimiaga, M.J., Bland, S., Skeer, M., Cranston, K., et al. (2010) Problematic Alcohol Use and HIV Risk among Black Men Who Have Sex with Men in Massachusetts. AIDS Care, 22, 577-587. http://dx.doi.org/10.1080/09540120903311482

[21] Bruce, D., Kahana, S., Harper, G.W. and Fernandez, M.I. (2013) Alcohol Use Predicts Sexual Risk Behavior with HIV-Negative or Partners of Unknown Status among Young HIV-Positive Men Who Have Sex with Men. AIDS Care, 25, 559-565. http://dx.doi.org/10.1080/09540121.2012.720363

[22] Silan, V., Kant, S., Haldar, P., Goswami, K., Rai, S.K. and Misra, P. (2013) HIV Risk Behavior among Men Who Have Sex with Men. North American Journal of Medical Sciences, 5, 515-522. http://dx.doi.org/10.4103/1947-2714.118931 